\title{
AN ESTIMATION METHOD FOR SEISMIC EFFECTS OF REINFORCED CONCRETE NON-STRUCTURAL WALLS TO STRUCTURAL FRAME MEMBERS
}

\author{
Masamichi Ohkubo*
}

\begin{abstract}
SUMMARY
To resolve the undesirable effects of reinforced concrete non-structural walls to the earthquake behaviour of structural members, weak points (called "Structural Slits") are intentionally provided at the connection between structural members and non-structural walls. This paper presents an estimation method for the stress developed in the "Structural Slits" which are applied to the non-structural walls of reinforced concrete high-rise residential buildings.
\end{abstract}

Editor's Note: This paper was first published in the Proceedings of the 1988 Pacific concrete Conference and is reprinted with the permission of the Cement and Concrete Association of New Zealand and the New Zealand Concrete Society.

\section{INTRODUCTION}

Recently in Japan, many high-rise buildings have been constructed for redevelopment in cities to use sites effectively and to deal effectively with the problems of land cost skyrocketing. Reinforced concrete frame type structures are very often adopted as the structural system for high-rise residential buildings, because of the low construction cost and the inherent high-stiffness for lateral forces.

In seismic design for high-rise buildings, two basic principles are required: 1) to clear the resisting mechanism to earthquake

forces and (2) to provide sufficient strength and ductility to the resisting mechanism planned. To respond to such principles, a beam-yield type's frame structure which has strong columns and ductile beams is planned. However, as various shapes of reinforced concrete non-structural walls are constructed with structural members using the same concrete materials, the clear resistingmechanism often is not realized by the effects of such non-structural walls. Each small exterior wall shown in Figure 1 , which represents part of a typical elevation of high-rise residential buildings developing in Japan, is also one of the non-structural walls. Such non-structural walls generate secondary stress into the frames subjecting them to lateral deformation. Figure 2

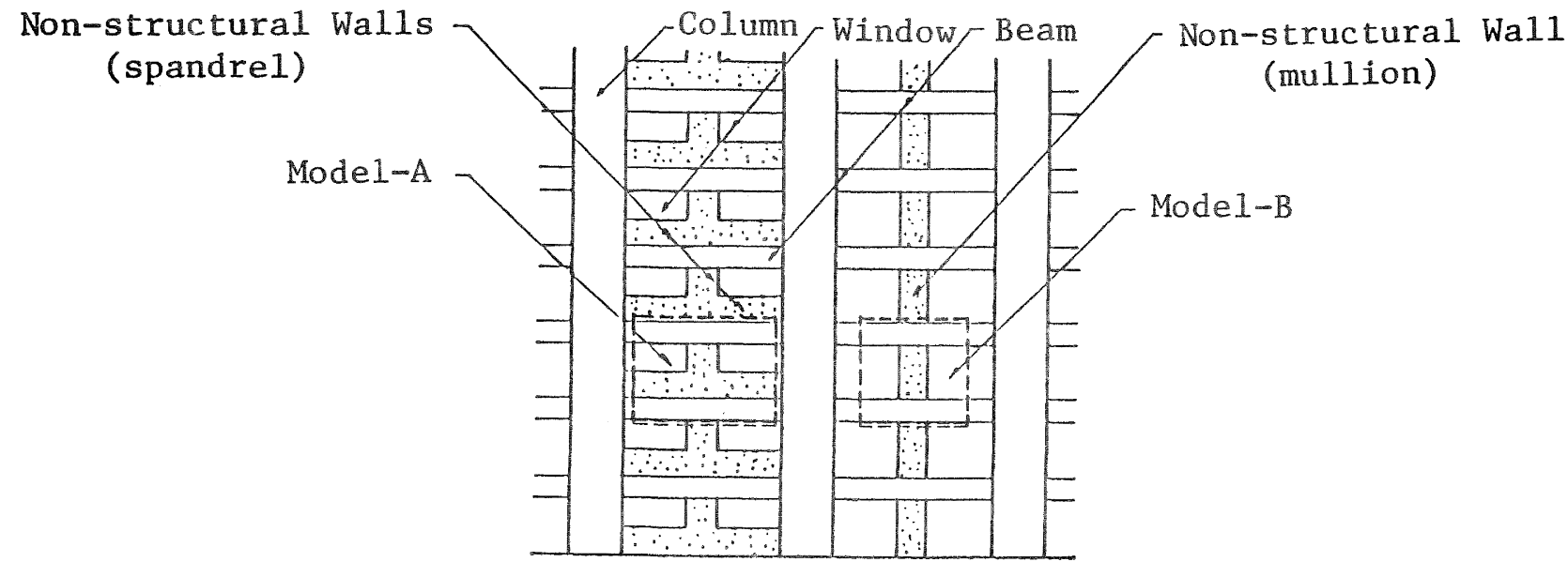

FIGURE 1: ILLUSTRATION OF NON-STRUCTURAI WALLS IN HIGH-RISE RESIDENTIAL BUILDINGS

* Kyushu Institute of Design 
Column
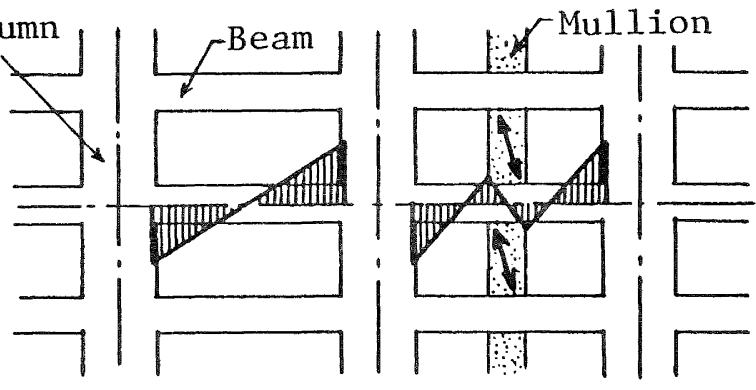

FIGURE $2:$ MOMENT DIAGRAMS OF BEAMS WITH OR WITHOUT NON-STRUCTURAL WALLS

illustrates the state of moment distribution on the beam with or without non-structural walls. In the beam with non-structural walls, because of secondary stress, the slope of moment diagram becomes more steep than the case without non-structural walls. Consequently, the frame may become a different mechanism from the original one planned. The beam becomes more susceptible to brittle shear-failure. If it is possible to remove such non-structural walls from the frame, the problem may be cleaned up. However, they are provided for such reasons as fire protection, sound insulation, construction cost, design of facade, etc., so it is not so easy to remove them for only a structural assertion.

To resolve comprehensively such problems as earthquake related problems and other requirements, weak points (called "Structural slits") to break intentionally in times of severe earthquake have been thought out and provided at the connections between structural members and non-structural walls. Figure 3 shows typical shapes of "Structural slits".
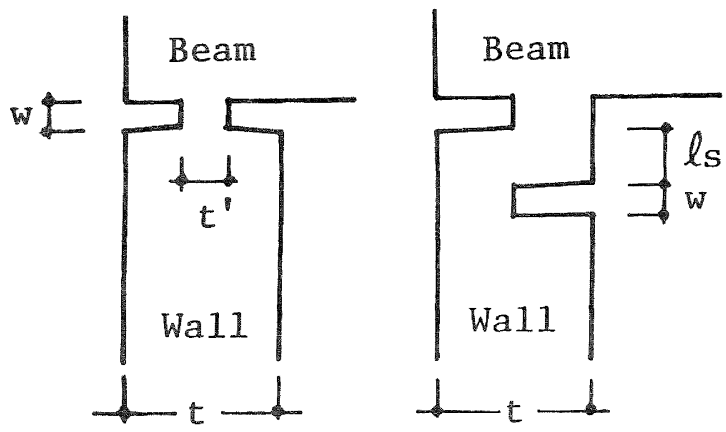

\section{Rectangular- Slit \\ Single-Shear Slit}

As "Structural slits" are planned to break themselves, it is necessary to know the possible maximum failure-capacity for their use. This paper presents an estimation method for the stress and capacity developed in "Structural slits". The equations for the estimates were based on the results from twelve tests in which the parts surrounded by broken lines in Figure I were modelled.

\section{TEST PROGRAMS}

The Objectives of the Tests

Two typical reinforced concrete nonstructural walls which form the exterior walls of high-rise residential buildings were modelled to test : Model-A combines a mullion type wall with a half-height spandrel; the other is the mullion type wall, Model-B.

The objective of the tests for Model-A is to determine a reasonable location for setting "Structural Slits". The objective of the tests for Model-B is to obtain data for stress developed in "Structural slits".

\section{Test Specimens}

The shapes and sizes of specimens are shown

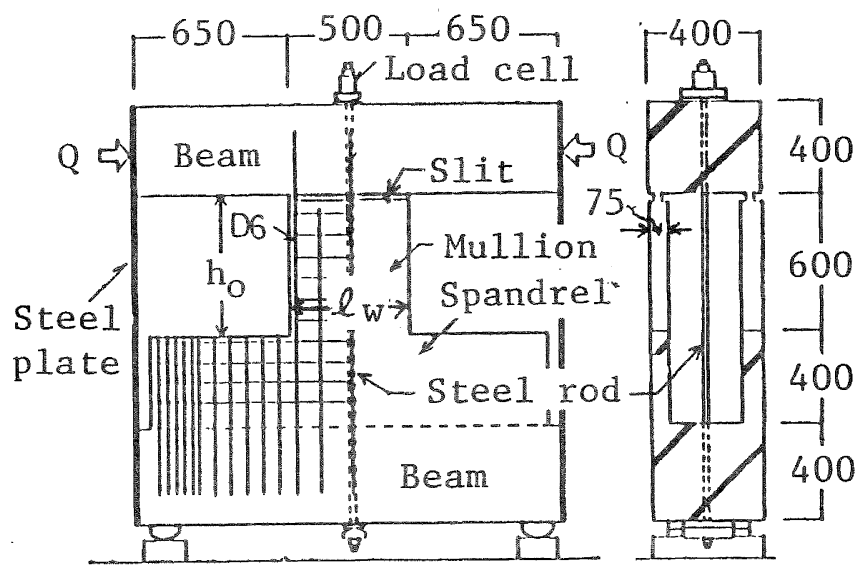

FIGURE $4:$ SHAPE AND SIZE OF TESTSPECIMENS

in Figure 4. Two same non-structural walls are opposite in a specimen. The adoption of the opposite-walls-system reflects consideration for stability of the specimen during tests.

In general, a reinforced concrete member shows the characteristics of longitudinal elongation which occurs by the development of cracks. The non-structural walls in a frame also must have such elongation, if there is little restriction for it. However, in the non-structural walls as shown in Figure 1, the development of longitudinal elongation due to lateral deformation may be restricted by the surrounding frame with strong columns. The arrangement of non-structural walls with the multi-storied condition may also restrict each elongation by itself. The thin flexible steel plates in either side of the specimen and the steel rod at the center of the specimen as shown in Figure 4 are set to restrict the longitudinal elongation in consideration of the condition mentioned above.

Two types of "Structural slits" are provided : the concave type (called Rectangular Slits") and the single shear type (called "Single shear Slits") shown in Figure 3. Normal stress is transmitted through the "Structural Slits" in the case of "Rectangular slits". Shearing stress is trans- 
TABLE 1 : THE LIST OF SPECIMENS

\begin{tabular}{|c|c|c|c|c|c|c|}
\hline \multirow[t]{2}{*}{ Specimen } & \multirow[t]{2}{*}{ Spandrel } & \multicolumn{2}{|c|}{ Mullion } & \multicolumn{2}{|c|}{ Structural slits } & \multirow{2}{*}{$\begin{array}{l}\text { Strength of Concrete } \\
\left(\mathrm{kgf} / \mathrm{cm}^{2}\right)\end{array}$} \\
\hline & & width & Height & Type & Location & \\
\hline No. 1 & with & $50 \mathrm{cn}$ & $60 \mathrm{~cm}$ & without & without & 234 \\
\hline No. 2 & with & $50 \mathrm{~cm}$ & $60 \mathrm{~cm}$ & RS, $30 \%$ & Top of Wall & 197 \\
\hline No. 3 & with & 50 & $60 \mathrm{~cm}$ & RS, $60 \%$ & Top of Wall & 197 \\
\hline No. 4 & with & $50 \mathrm{cn}$ & $60 \mathrm{~cm}$ & SS & Side of Wall & 197 \\
\hline No. 5 & with & $50 \mathrm{cr}$ & $60 \mathrm{~cm}$ & RS, $30 \%$ & Side \& Bottom & 197 \\
\hline No. 6 & with & $50 \mathrm{ch}$ & $60 \mathrm{~cm}$ & SS & Side \& Bottom & 197 \\
\hline No. 7 & without & $50 \mathrm{cn}$ & $100 \mathrm{~cm}$ & without & without & 197 \\
\hline No. 8 & without & $50 \mathrm{cn}$ & $100 \mathrm{~cm}$ & $\mathrm{RS}, 30 \%$ & Bottom & 270 \\
\hline No. 9 & without & $50 \mathrm{cr}$ & $100 \mathrm{~cm}$ & RS, $60 \%$ & Bottom & 197 \\
\hline No. 10 & without & $50 \mathrm{cr}$ & $100 \mathrm{~cm}$ & SS & Bottom & 238 \\
\hline No.11 & without & $30 \mathrm{cr}$ & $100 \mathrm{~cm}$ & RS, $30 \%$ & Bottom & 180 \\
\hline No. 12 & without & $90 \mathrm{cn}$ & $100 \mathrm{~cm}$ & RS, $30 \%$ & Bottom & 270 \\
\hline
\end{tabular}

RS : Rectangular Slits, SS : Single Shear slits

TABLE 2 : PROPERTIES OF REINFORCING BARS

\begin{tabular}{lccc}
\hline Size of Bar & Yield Strength & Strain at Yield & Tensile Strength \\
\hline D6 (for wall) & $3650 \mathrm{~kg} / \mathrm{cm}^{2}$ & $0.22 \%$ & $5280 \mathrm{~kg} / \mathrm{cm}^{2}$ \\
D22(for beam) & $3840 \mathrm{~kg} / \mathrm{cm}^{2}$ & $0.24 \%$ & $5800 \mathrm{~kg} / \mathrm{cm}^{2}$ \\
\hline
\end{tabular}

D6 : Deformed bars with nominal diameter, $6 \mathrm{~mm}$

D22 : Deformed bars with nominal diameter, $22 \mathrm{~mm}$.

mitted in the case of "Single shear slits". In the "Rectangular slits", two kinds of "Structural Slits" (in which the net wall thickness at the part of "Structural slits" was reduced to $30 \%$ of the entire wall thickness [called $30 \%$ offset] and to $60 \%$ [called $60 \%$ offset] are provided for the tests. The non-structural walls without "Structural Slits" (Specimens No. 1 and No. 7) are also provided as companion specimens. The thickness of the wall is $7.5 \mathrm{~cm}$, about one half of the actual thickness. The features of each specimen are summarized in Table 1. The properties of the materials used are shown in Table 2 .

\section{Loading and Measuring}

Both supports of the bottom beam, assuming the inflection points of the frame, were provided for the condition of simplesupport. Lateral load-reversals for positive and negative loading were applied alternately from one side of the top beam. The loads and the displacement during tests was controlled on the basis of the horizontal displacement at the top beam corresponding to a story-drift.

The data concerned with lateral loads, displacements, strains of side-plates, forces of the steel rod for longitudinal restriction to the non-structural wall, strains of reinforcing bars and the surface concrete, etc., were measured at each loading step.

\section{TEST RESULTS}

The Forces Developed in Non-Structural Walls

The relation between the lateral loads (Q) and the drift angles (R) of each specimen are shown in Figure 5 by the enveloped curves for cyclic loading. The failure modes after the test in each specimen are shown in Figure 6 . The failure mode of the opposite wall not presented here was similar to Figure 6 in each specimen, respectively.

No. I specimen, in which the "Structural Slits" were not provided, failed by brittle behaviour due to diagonal tension. The diagonal tension cracks occurred at about 0.004 radian of drift-angles. In No. 2 specimen with "Rectangular Slits of $30 \%$ offset" at the top of the wall, the

"Structural Slits" crushed in overall width by diagonal compression and simultaneously slipped horizontally. In No. 3 specimen with "Rectangular Slits of $60 \%$ offset", the "Structural Slits" crushed partially only near the corner. Diagonal tension cracks occurred, and covered concrete of the top beam failed by splitting.

In the specimens Nos. 4 - No. 6, in which "Structural slits" were provided vertically or with U-shape in the spandrels, diagonal tension cracks did not occur. In No. 6 specimen with the "Single-Shear slits", the damage was concentrated at the slit-zone. The force developed in non-structural walls 


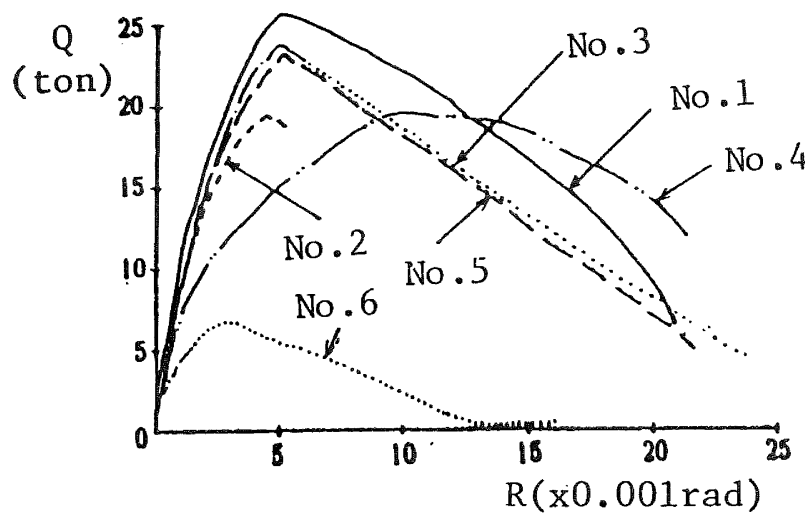

a) Specimen No. 1 - No. 6

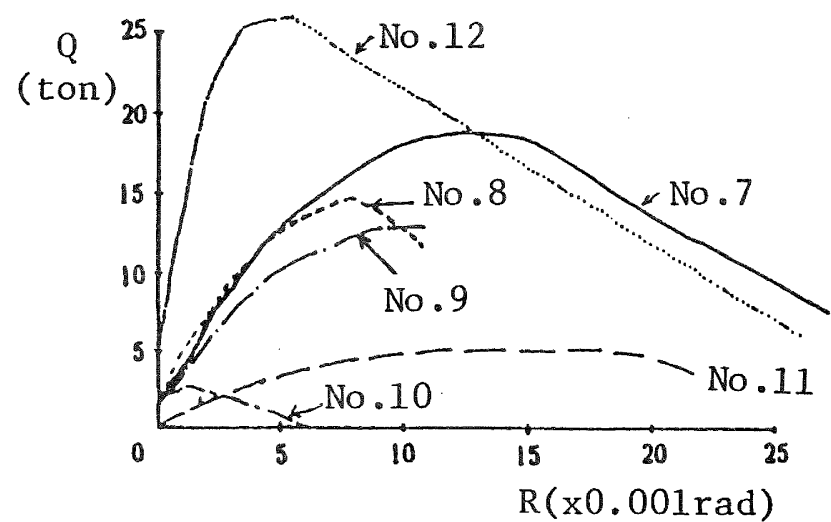

b) Specimen No. 7 - No. 12

FIGURE 5 : ENVELOPED CURVES OF RELATION BETWEEN LATERAL LOAD (Q) AND DRIFT-ANGLE (R)
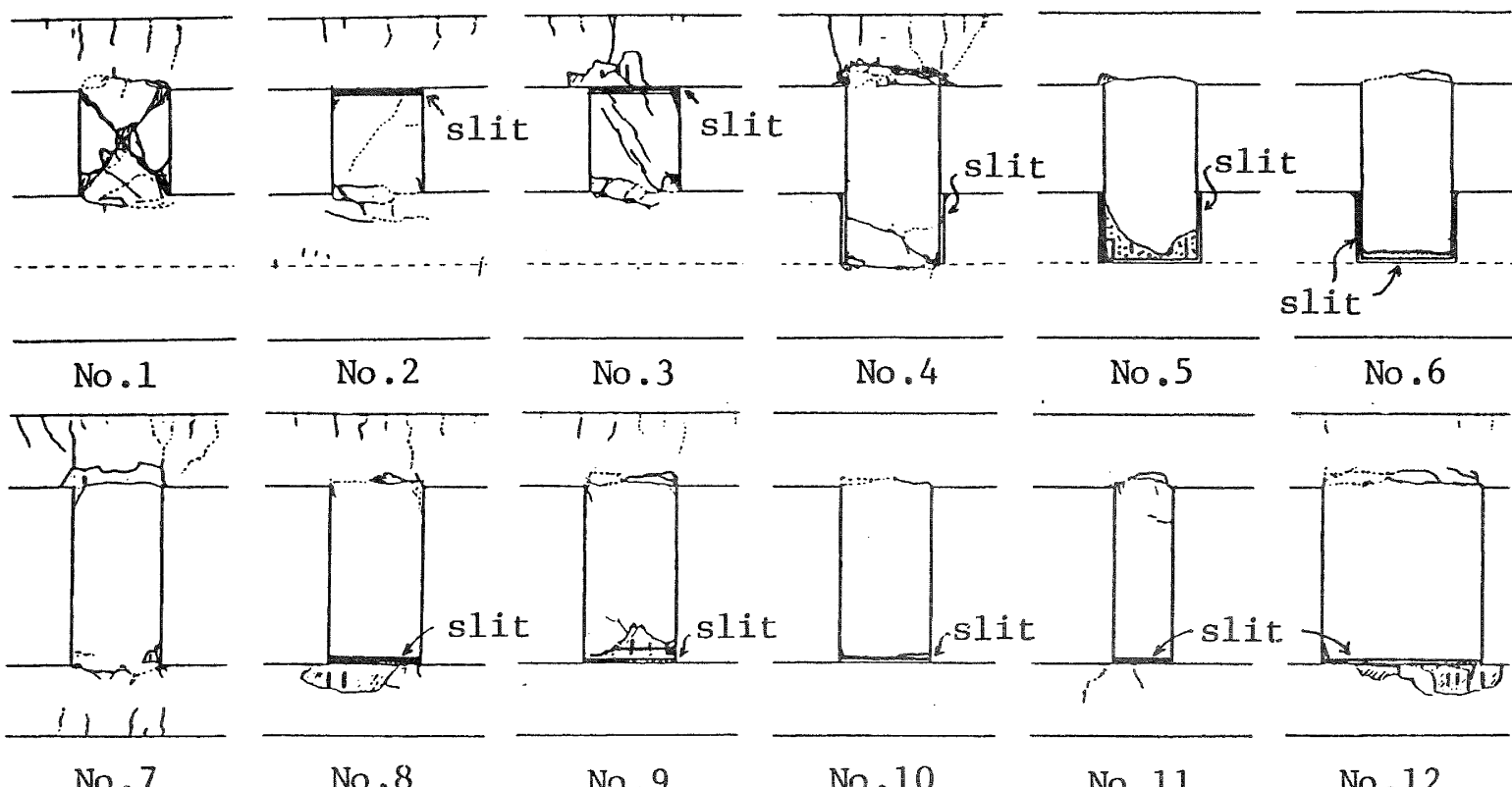

No. 7

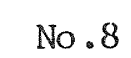

No. 9

No. 11

No. 12

FIGURE $6:$ FAILURE MODES OF EACH SPECIMEN AFTER TEST

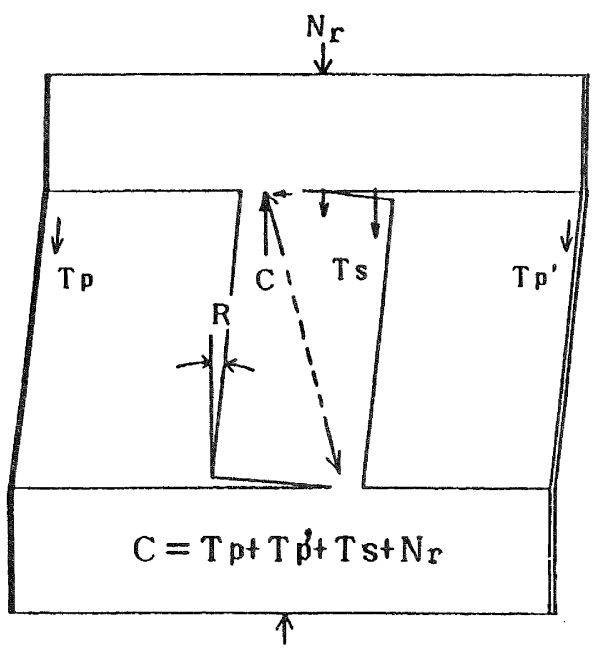

FIGURE 7 : EQUILIBRIUM OF VERTICAL FORCES IN THE SPECIMEN

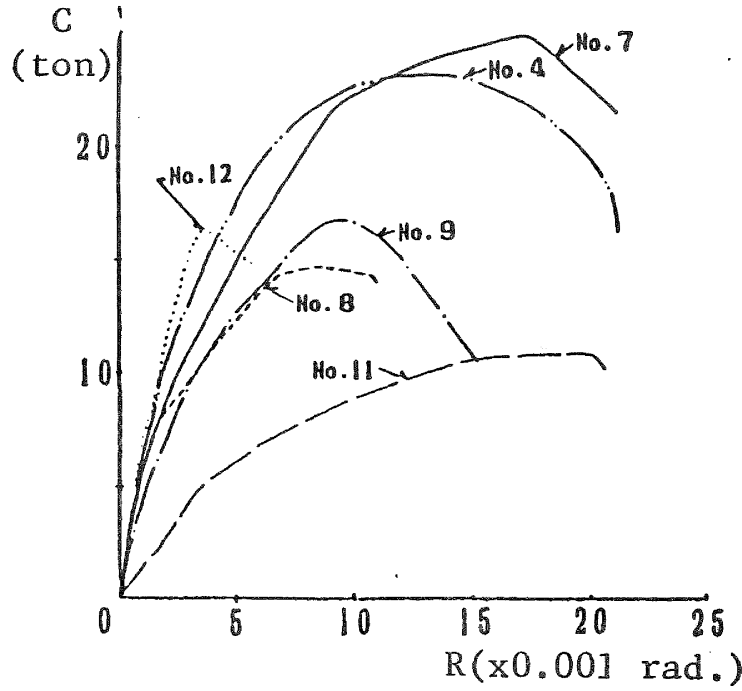

FIGURE 8 : COMPRESSION FORCES IN NONSTRUCTURAL WALLS. 
was remarkably small compared to the No.4 and No. 5 specimens. Although the "SingleShear slits" has difficulties for construction and for rainproofing, it offers excellent performance for mitigation of forces developed in non-structural walls and also for control of damage in non-structural walls.

The Forces Exerted on Beams From NonStructural Walls

Figure 7 illustrates the vertical forces exerted on the upper half of the specimen. The force (C) of compression zone at the corner is expressed by Eq. (1).

$$
C=T_{p}+T_{p}^{\prime}+T_{s}+N_{r}
$$

where, $T_{p}$ and $T_{p}^{\prime}$ are the restrictive force in each $\mathrm{side}$ of $\mathrm{p}_{\mathrm{he}}$ steel plates, $\mathrm{T}_{\mathrm{S}}$ is the tensile force of reinforcing bars in the wall, and $\mathrm{N}_{r}$ is the external restriction force by steel rod without prestress.

Figure 8 shows the compressive force (C) obtained by Eq. (I) using measured $T_{p}, T_{p}$, $\mathrm{T}_{\mathrm{S}}$ and $\mathrm{N}_{r}$. The horizontal axis presents drift-angles $(R)$.

In the specimens with "Structural slits", the compressive forces are mitigated by the effects of "Structural slits". If the compressive forces are estimated originally, they could be projected to the seismic design of beams with non-structural walls.

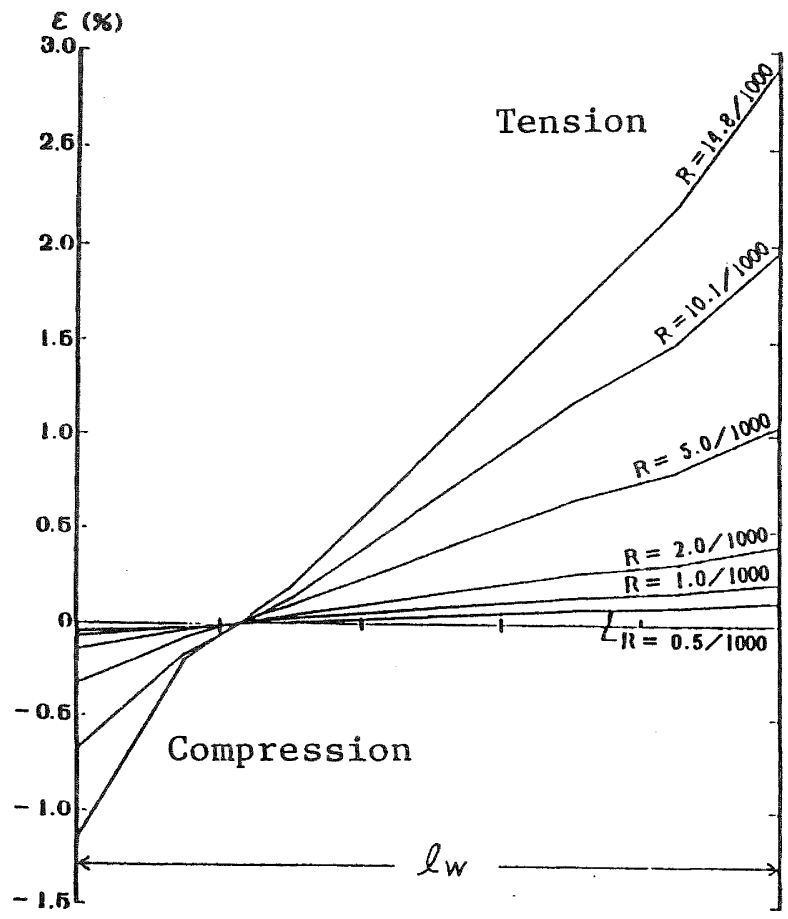

FIGURE 9 : STRAIN DISTRIBUTION AT THE TOP OF NON-STRUCTURAL WALL
The Behaviour of Non-structural Walls During Tests

Figure 9 shows the distribution of longitudinal strains along the connection between the wall and the beam. As shown in the figure, the strain distribution is approximately linear in each range of drift-angle. Figure 10 shows the relation between the drift-angle $(R)$ and the rotation angle $\left(\theta_{j}\right)$ which is measured at the end of the wall with "Structural slits". It is observed that $\theta_{j}$ is approximately the same as R in the range before the failure of "Structural slits". This seems to indicate that the non-structural wall between the top and the bottom almost behaves as a rigid body.

\section{ESTIMATION OF COMPRESSION FORCE DEVELOPED}

\section{IN "STRUCTURAL SLITS"}

Assumptions to Express the Equation of Compression Force

The following is assumed to precede the equation for estimation of the compression force (C) in "Structural slits". (See Figure 11).

1) The distance between top and bottom beam, ho is kept constant during loading. 2) The non-structural wall behaves as a rigid body. The drift angle $(R)$ is the same as the rotation angle $\left(\theta_{j}\right)$ at the end of the wall with "Structural Slits".

3) The triangular compressive strain-zones are formed at the top and the bottom end of the wall.

4) The ratios of the strains at both compression fibres $\left(\alpha=\varepsilon_{\mathrm{W}} / \varepsilon_{j}\right)$ are proportional to the offset ratios of wall thickness. (See Figure 12).

5) The nominal deformations sunk into beams is $0.1 h_{0}$ times the fibre strain in each compression zone.

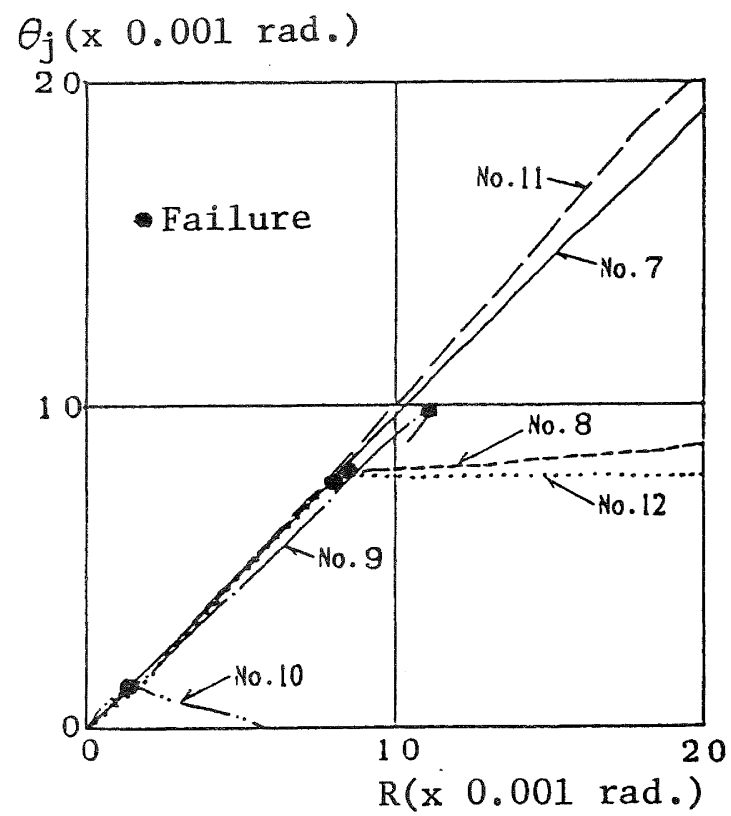

FIGURE 10 : RELATION BETWEEN $\theta_{j}$ AND R 


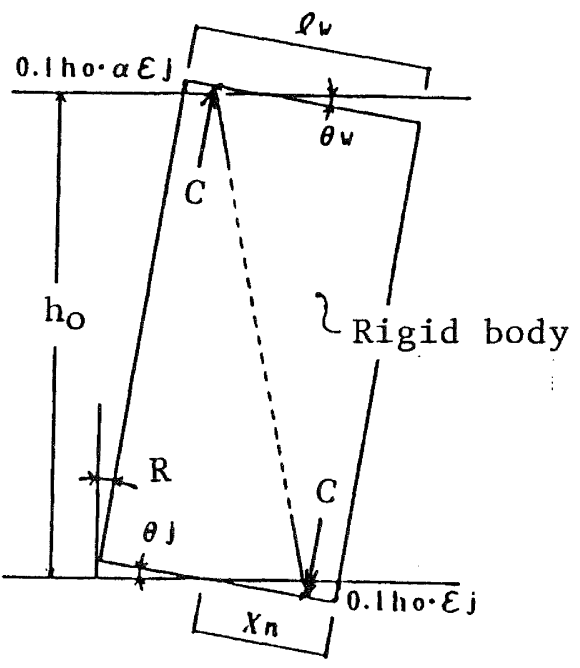

FIGURE 11 : MODEL ASSUMED FOR ESTIMATION OF COMPRESSION FORCE

The Length of Compression Zone in

\section{"Structural slits"}

The relation between the drift-angle (R)

and the compression fibre strain $\left(\varepsilon_{j}\right)$ in

the "Structural Slits" is expressed in

Eq. (2) from the geometric deformation on the above assumptions.

$$
\begin{aligned}
R & =\sin ^{-1}\left(\frac{h_{0}}{\sqrt{\ell_{w}^{2}+h_{0}^{2}\left(1-0 \cdot 1(1+\alpha) \cdot \varepsilon_{j}\right)^{2}}}\right) \\
& -\tan ^{-1}\left(\frac{h_{0}\left(1-0 \cdot 1(1+\alpha) \cdot \varepsilon_{j}\right)}{l_{w}}\right)
\end{aligned}
$$

where, $\ell_{w}$ and $h_{0}$ are the width and the height of the non-structural wall, respectively. The length of compression zone in the "Structural Slits", $\left(\mathrm{x}_{\mathrm{n}}\right)$ is expressed by Eq. (3), see Figure 11.

$$
x_{n}=0.1 h_{0} \cdot \varepsilon_{j} / \tan R
$$

Comparison of Estimated Values with Test Results

Applying the "e-function expression" proposed by Dr. H. Umemura [1] for the stress-strain relationships of concrete in compression, the maximum compressive resultants $\left(\mathrm{C}_{\max }\right)$ developed in the zone $\left(\mathrm{x}_{n}\right)$ were calculated for each specimen. The results calculated are presented in Table 3 compared with the test results. The estimated values for the specimens in which concretecrushing occurred in "Structural slits" are comparatively close to the measured values. In No. 1 specimen, in which the shear failure occurred prior to the concrete-crushing, and in No. 12 specimen, in which the failure of covered concrete occurred without any crushing in "Structural slits", the measured values are lower than the estimation.

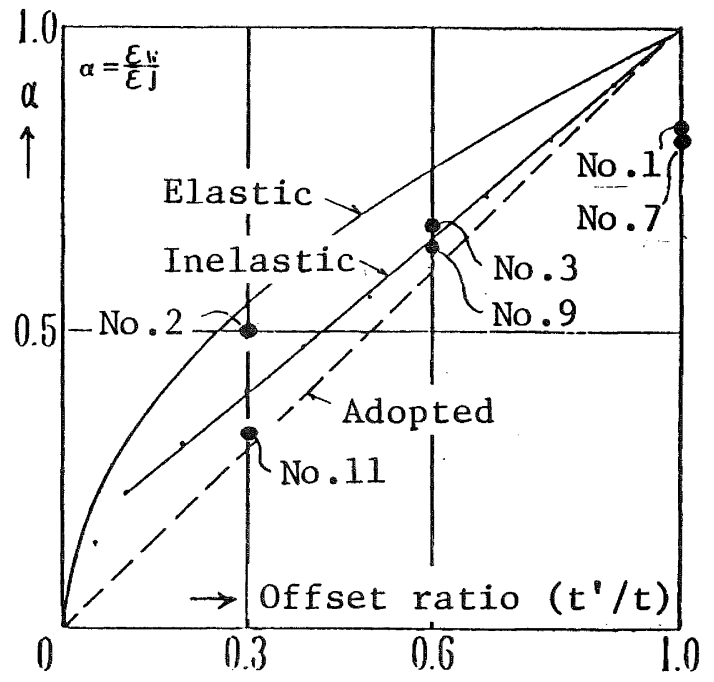

FIGURE 12 : RELATION BETWEEN $\alpha$ AND $\left(t^{\prime} / t\right)$

INTRODUCTION OF EFFECTS BY NON-STRUCTURAL TO STRUCTURAL DESIGN

The effects of compression forces developed in non-structural walls which were arranged with the multi-storied condition could be dealt as a coupled moment, as shown in Figure 13, and could be expressed by Eq. (4). The secondary moments and shear forces due to Figure 13 should be added to the original frame-stresses analysed for the frame without non-structural walls.

$$
M=C \times J_{W}
$$

where, $\mathrm{C}$ is the resultant compressionforce, and $J_{W}$ is the distance between the coupling forces (C).

Additional stress by
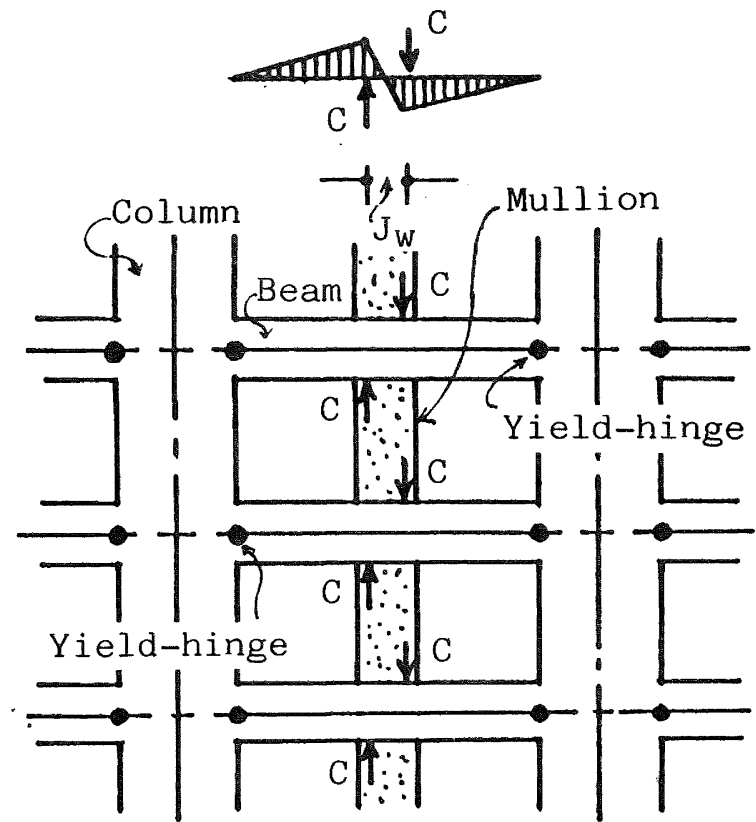

FIGURE 13 : COUPLING FORCE EXERTED ON BEAMS FROM NON-STRUCTURAL WALLS 
TABLE 3 : COMPRESSION FORCES (C:tonf) AND FAILURE MODES

\begin{tabular}{lccccccccc}
\hline Specimen No. & 1 & 2 & 3 & 4 & 7 & 8 & 9 & 11 & 12 \\
\hline C (measured) & 20.71 & 15.00 & 20.54 & 23.48 & 25.20 & 16.06 & 19.43 & 10.92 & 16.52 \\
C (estimated) & 35.66 & 13.86 & 22.52 & 30.02 & 30.02 & 18.99 & 22.52 & 8.01 & 34.19 \\
Failure mode & D.T. & Fj & Fj-Fb & Fb & Fb & Fj-Fb & Fj-FW & Fj & Fb \\
\hline
\end{tabular}

D.T. : Diagonal tension, Fj : Crushing in slits, Fb : Splitting failure of covered concrete of beam bottom, $F W$ : Splitting failure of wall.

TABLE 4 : DISTANCE OF COUPLING FORCES $\left(\mathrm{J}_{\mathrm{w}} / \ell_{\mathrm{w}}\right)$

\begin{tabular}{lcccccccccc}
\hline Specimen No. & 1 & 2 & 3 & 4 & 5 & 7 & 8 & 9 & 11 & 12 \\
\hline Method-1 & 0.80 & - & - & - & - & - & 0.68 & 0.74 & 0.72 & 0.72 \\
Method-2 & 0.62 & 0.64 & 0.64 & 0.66 & 0.66 & 0.58 & 0.82 & 0.73 & 0.71 & 0.82 \\
Method-3 & 0.70 & 0.76 & 0.68 & 0.79 & 0.68 & 0.59 & 0.87 & 0.65 & 0.59 & 0.84 \\
\hline
\end{tabular}

Method-1 : obtained from principal strain at the centre of wall,

Method-2 : obtained from the equilibrium of moment (See Figure 7),

Method-3 : obtained from the direction of diagonal compression strut combined lateral force (Q) with compression force (C).

Eq. (5) is the compression force normalized by the width and the thickness of the nonstructural wall and concrete strength. It was the equation in which the compression forces estimated using $\mathrm{Eq}$. (3) and "efunction stress-strain relationships" for concrete were approximated by the least Square method. Figure 14 shows Eq. (5) compared with the test results.

$$
\begin{aligned}
B & =C /\left(t e_{W} \cdot F_{C}\right) \\
& =\left(t^{\prime} / t\right)\left(0.7-0.3\left(t^{\prime} / t\right)\right)
\end{aligned}
$$

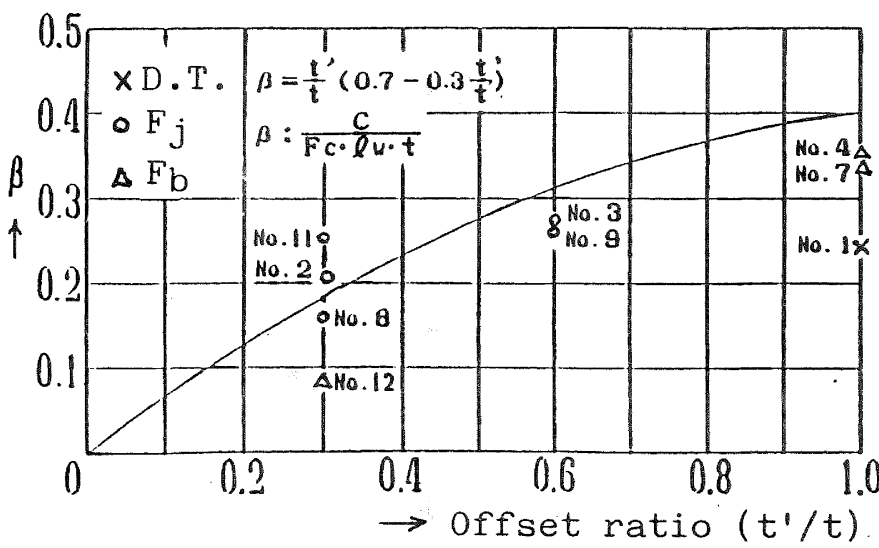

FIGURE 14 : RELATION BETWEEN NORMALIZED COMPRESSION FORCE ( $\beta$ ) AND OFFSET RATIO $\left(t^{\prime} / t\right)$

For $J_{W}$ in Eq. (4), the following Eq. could be recommended. It was obtained considering that the average of $\mathrm{J}_{\mathrm{W}}$ analysed by some methods was approximately $0.7 l_{\mathrm{w}}$ as shown in Table 4 .

$$
J_{W}=0.7 \ell_{W}
$$

FAILURE MODES IN THE PART OF "STRUCTURAL SLITS"

Three failure modes were observed in the specimens with the "Rectangular Slits" as mentioned above : 1) concrete-crushing in "Structural Slits", 2) splitting failure of covered concrete of the beam adjacent to "Structural slits" and 3) splitting failure of the wall adjacent to "Structural slits".

Figure 15 illustrates the possible failure modes in the part of "Structural Slits". The mode of concrete-crushing $\left(\mathrm{F}_{j}\right)$ depends on the strength of the offset-concrete in "Structural Slits". The mode of splitting failure in the covered concrete of the beam $\left(F_{b}\right)$ depends on the bearing strength of beam-concrete subjected to compression force from "Structural slits". The mode of splitting failure in the wall $\left(F_{w}\right)$ also depends on the bearing strength of wallconcrete subjected to the same compression from "Structural slits".

Eqs. (7), (8) and (9) show each strength corresponding to the above three failure modes. The strength-increase due to sizeeffect is considered in Eq. (7) for the concrete-crushing strength of "Structural Slits", using the proposal by Dr. Baushinger [2]. The proposal by Prof. H. Muguruma is adopted for the bearing strengths of concrete in beams and walls shown in Eqs. (8) and (9), respectively [3]. 


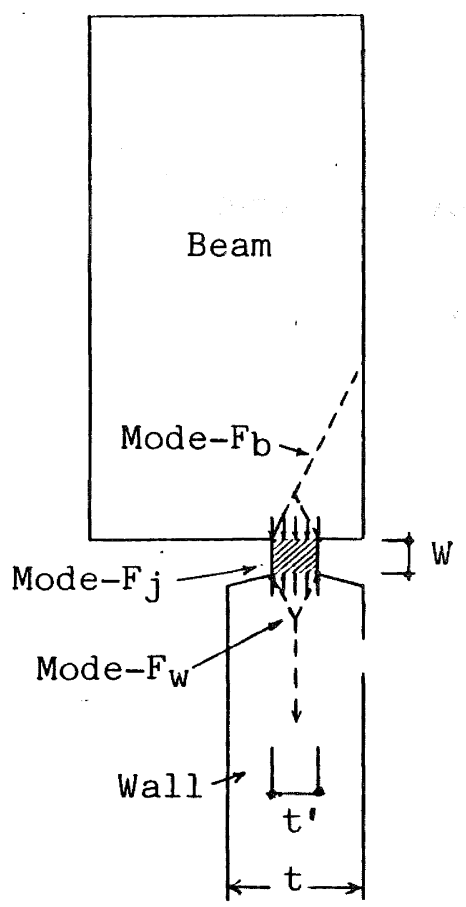

FIGURE 15 : POSSIBLE FAILURE-MODES

$$
\begin{aligned}
& P_{u j}= 0.95+ \\
&\left.0.2\left(t^{\prime} / w\right)^{2}\right) t^{\prime} F_{C} \\
& {\left[\text { for mode } F_{j}\right] } \\
& P_{u b}=1.02\left(t^{\prime} / t\right)^{0.55} \cdot t \cdot F_{C} \\
& \\
& {\left[\text { for mode } F_{b}\right] } \\
& P_{u w}=0.95\left(t^{\prime} / t\right)^{0.54 \cdot t \cdot F_{C}} \\
& {\left[\text { for mode } F_{w}\right] }
\end{aligned}
$$

where, $F_{C}$ is the cylindrical strength of concrete, and see Figure 15 for the notations of $t^{\prime}, t$ and $w$.

Figure 16 shows the relationship among the three strengths. The strength $\mathrm{P}_{u_{b}}$ is larger than $\mathrm{P}_{\mathrm{uw}}$ in every case. The possible failure of concrete-crushing in "Structural slits" is observed in the range less than about $0.5\left(t^{\prime} / t\right)$.

\section{CONCLUSIONS}

In the seismic design of buildings, not only the design for structural frames but also the discussion for non-structural elements should be required. Especially, in the case where the mechanism of ductile moment-resistance is expected, the effects of secondary stress exerted from non-structural elements should be considered to prevent the occurrence of yield-hinges on the unexpected points in frames. The equations shown in this paper are appropriate for estimation of secondary stress by mullion-shaped reinforced concrete non-structural walls.

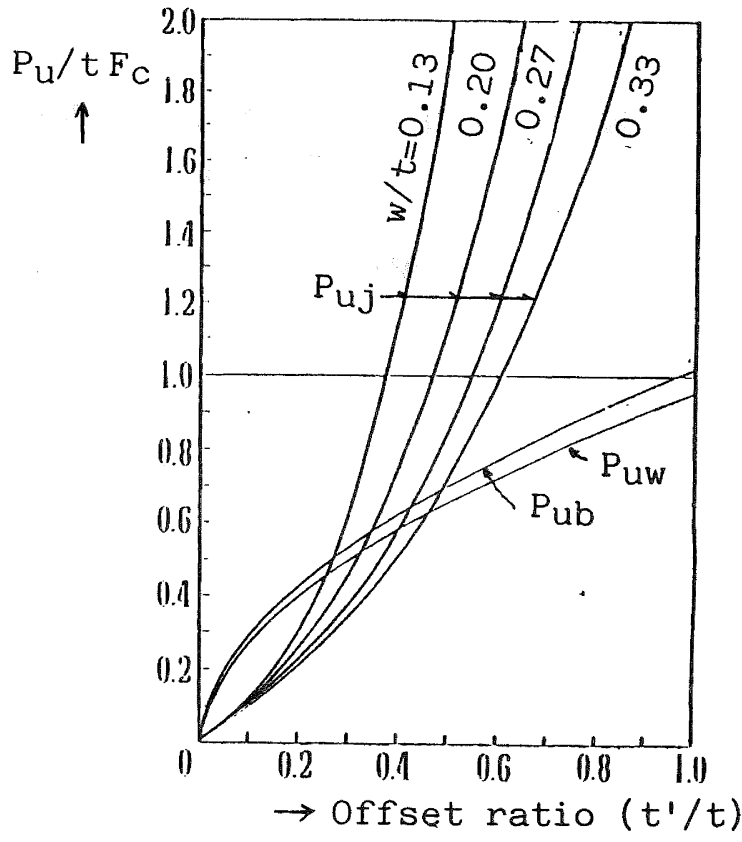

FIGURE 16: RELATION BETWEEN FAILURE CAPACITY ON THE PART OF STRUCTURAL SLITS $\left(P_{u}\right)$ AND OFFSET RATIO $\left(t^{\prime} / t\right)$

\section{REFERENCES}

[1] K. Muto ; Seismic Design Series 2 (Inelastic Design of Reinforced Concrete Structures), Maruzen Co. 1964. (in Japanese).

[2] A Compendium of Architecture, Vol. 13 (Architectural Materials), Shokokusha Co., 1976. (in Japanese).

[3] H. Muguruma and S. Okamoto ; Experimental Studies on Bearing Strength of Concrete Subjected to Partial Loads, Trans. of Cement Assoc., Japan, Vol.12, 1963 and Vol.13, 1964. (in Japanese).

\section{ACKNOWLEDGEMENT}

The tests reported in this paper were carried out using a research grant from the committee on "Studies of Reinforced Concrete High-rise Residential Buildings" chaired by Prof. H. Aoyama and promoted in the Architectural Institute of Japan. The suggestions for tests by the committee members are deeply acknowledged. S. Shioya, K. Yamamoto, T. Anoh and T. Harada's cooperation in the tests and the analyses are also deeply acknowledged. The suggestions for this paper by Prof. C.A. De Deurwaerder are deeply acknowledged. 